\title{
ANALISIS KEUNTUNGAN DAN KELAYAKAN EKONOMI USAHATANI TEMBAKAU VIRGINIA DI KABUPATEN LOMBOK TENGAH
}

\author{
Muhammad Nursan $^{1^{*}}$, Candra Ayu ${ }^{1)}$ Pande Komang Suparyana ${ }^{1)}$ \\ ${ }^{1}$ Mataram University, Indonesia \\ ${ }^{*}$ Corresponding author : mnursan@yahoo.co.id \\ To cite this article: \\ Nursan, M., Ayu, C., \& Suparyana, P. (2020). Analisis Keuntungan dan Kelayakan Ekonomi Usahatani \\ Tembakau Virginia di Kabupaten Lombok Tengah. Jurnal Ilmiah Membangun Desa dan Pertanian, 5(3), \\ 104 - 110. doi:http://dx.doi.org/10.37149/jimdp.v5i3.11825
}

Received: April 25, 2020; Accepted: June 29, 2020; Published: June 30, 2020

\begin{abstract}
Virginia tobacco is one of the most cultivated plants by farmers on Lombok Island, one of which is in the Central Lombok Regency. Virginia tobacco farming is one source of farmers' income because the income generated is quite high. Therefore, the purpose of this research is to find out the benefits of Virginia tobacco farming in Central Lombok Regency and to analyze the economic viability of Virginia tobacco farming in Central Lombok Regency. This research using a descriptive research method, and it was conducted in Janapria District, Central Lombok Regency, which was selected by purposive sampling with consideration of the area with the highest area and number of Virginia tobacco farming production. Data sources in this study include primary data and secondary data. Primary data was collected by a survey method of 30 respondents, where the selection of respondents is done by accidental sampling techniques. Data analysis in this study uses economic feasibility analysis including R/ C ratio and $B$ / $C$ ratio analysis. The results showed that the average profit of Virginia tobacco farming is Rp.42,349,763/hectare and Virginia Tobacco Farming in Central Lombok Regency is economically feasible because it has an economic viability value of $R / C$ ratio of 1.9 and $\mathrm{B} / \mathrm{C}$ ratio of 0.9 .
\end{abstract}

Keywords: Central Lombok Regency; economic feasibility analysis; farming; virginia tobacco

\section{PENDAHULUAN}

Tembakau merupakan jenis tanaman perkebunan yang banyak dibudidayakan karena keuntungan yang diperoleh oleh petani cukup tinggi sehingga tanaman ini layak untuk dibudidayakan oleh petani di Indonesia khususnya di NTB. Disamping itu tanaman ini juga mempunyai nilai ekonomis tinggi dan berperan penting terhadap perekonomian di Indonesia seperti penyediaaan lapangan pekerjaan, sumber pendapatan petani, sumber devisa serta sebagai penunjang agribisnis dan agroindustri tembakau (Cahyono, 2011). Saat ini dengan adanya pengembangan industri tembakau tersebut, telah banyak memberikan dampak positif terhadap perekonomian seperti penerimaan cukai tembakau mencapai sebesar Rp138,69 triliun, mampu menyerap dan mendistribusikan sebesar 4,28 juta orang tenaga kerja pada sektor manufaktur serta sebanyak 1,7 juta orang tenaga kerja pada sektor sektor perkebunan (Kementerian Perindustrian, 2016).

Di Indonesia tembakau dibudidayakan sebagai tanaman komersial dengan rata-rata area tanam seluas 230.810 hektar dengan produksi rata-rata mencapai sebesar 197.037 ton selama kurun waktu tahun 2009-2013 (Dirjenbun, 2014). Saat ini, tanaman tembakau telah dibudidayakan hampir di seluruh provinsi dengan area tanam terbesar berada di Jawa Timur 48\%, Nusa Tenggara Barat $24 \%$, dan sisanya $28 \%$ di provinsi lainnya (Djajadi, 2015). Tembakau tersebut memiliki karakteristik ekologi yang berbeda yang disebabkan oleh kondisi lingkungan sehingga berpengaruh pada morfologi dan karakteristik tembakau (Suwarso, 2014). Selain itu, kualitas tembakau juga sangat dipengaruhi oleh jenis karakteristik tanah, ketinggian dan kemiringan tanah, serta kelembapan tanah (Brata, 2012).

Jenis tembakau yang banyak dibudidayakan di Indonesia adalah tembakau virginia. Provinsi Nusa Tenggara Barat menjadi salah satu daerah penghasil terbesar tembakau virginia dengan luas areal sebesar 27,2 ribu hektar, dengan jumlah produksi yang dihasilkan sebesar 39,6 ribu ton pada 
tahun 2017 (BPS Provinsi NTB, 2018). Salah satu daerah penghasil tembakau virginia di Provinsi NTB adalah Kabupaten Lombok Tengah dengan luas area tanam sebesar 10.625,10 hektar dan produksi yang dihasilkan mencapai sebesar 18.641,42 ton (BPS Kabupaten Lombok Tengah, 2018). Tingginya area dan produksi tembakau virginia di Kabupaten Lombok tengah ini dikarenakan usahatani tembakau Virginia masih merupakan usahatani utama setelah tanaman padi dan banyak dilakukan petani karena potensi pendapatan yang tinggi dan pendapatan petani dalam melakukan usahatani tembakau juga jauh lebih besar daripada melakukan usahatani padi (Hayati \& Maisaroh, 2019). Selain itu, besar kecilnya pendapatan usahatani tembakau juga sangat tergantung pada beberapa faktor diantaranya pola kemitraan (Hamidi, 2010), status penguasaan lahan (Winarso, 2012), pengalaman bertani, pendidikan, penguasaan teknologi, penguasaan pasar dan permodalan (Sumartono, 2016) serta pelatihan untuk meningkatkan pengetahuan dan keterampilan (Nursan \& Utama, 2019). Akan tetapi, meskipun komoditas tembakau dapat memberikan tingkat pendapatan yang tinggi pada petani juga dihadapkan dengan resiko yang tinggi pula karena maraknya promosi anti rokok pada berbagai negara termasuk Indonesia (Ambariyanto \& Herawati, 2010) dan adanya legalisasi hukum pembatasan produksi dan pemasaran rokok yang akan menurunkan permintaan tembakau sehingga dapat berakibat pada usahatani tembakau (Hasan \& Darwanto, 2013).

Saat ini potensi lahan untuk pengembanagan tanaman tembakau Virginia di Kabupaten Lombok Tengah sangat menjanjikan dimana biasanya petani menanam tembakau pada lahan sawah setelah selsai menanam padi di musim kering. Hal ini dikarenakan bahwa tembakau Virginia mampu memberikan tingkat keuntungan yang lebih tinggi dari jenis tanaman lainnya seperti padi, kacang hijau, jagung, umbi, kedelai dan kacang tanah, dan juga dinilai memiliki kelayakan yang tinggi karena keuntungan dan penerimaan yang dihasilkan jauh lebih tinggi dari total biaya usahatani. Seperti pada temuan penelitian terdahulu di daerah lain diantaranya Halil (2013) di Pulau Lombok dan Nazam et al., (2014) di Kabupaten Lombok Timur yang dalam penielitiannya menemukan bahwa usahatani tembakau Virginia sangata menguntungkan baik dengan skema mitra maupun non mitra. Disamping faktor lahan dan waktu tanam, yang mendukung petani di Kabupaten Lombok tengah melakukan budidaya tembakau virgina adalah petani memiliki pengetahuan dan teknologi yang memadai dalam melakukan usahatani tembakau virginia sehingga dinilai akan mampu memberikan keuntungan dan kelayakan usaha yang lebih tinggi. Penelitian ini bertujuan untuk mengetahui keuntungan dan menganalisis kelayakan ekonomi usahatani tembakau virginia di Kabupaten Lombok Tengah.

\section{MATERI DAN METODE}

Penelitian ini dilakukan mulai pada bulan Oktober sampai dengan bulan Desember tahun 2019 betempat di Kecamatan Janapria Kabupaten Lombok Tengah, Provinsi Nusa Tenggara Barat. Lokasi penelitiandipilih secara purposive sampling dengan pertimbangan lokasi penelitian merupakan salah satu daerah dengan luas dan jumlah produksi tembakau virginia tertinggi di NTB. Sumber data penelitian terdiri atas data primer dan data skunder. Data primer d dikumpulkan dengan metode survey terhadap 30 responden yang dipilih secara accidental sampling(Sugiono, 2017).

Data penelitian yang terkumpul kemudian dianalisis mengunakan persamaan keuntungan untuk mengetahui besar keuntungan usahatani tembakau virginia di Kabupaten Lombok Tengah. Persamaan keuntungan yang digunakan adalah persamaan keuntungan (Soekartawi, 2011) dan (Suratiyah, 2015) yang digunakan juga oleh Fauziyah et al., (2010), (Halil, 2013), Tarigan et al., (2013), Nazam et al., (2014), Putri et al., (2015) dan Manalu et al., (2018) dalam menghitung keuntungan usahatani tembakau di berbagai daerah di Indonesia. Adapun persamaan keuntungan usahatani dapat ditulis sebagai berikut:

$$
\pi=\mathrm{TR}-\mathrm{TC}
$$

Dimana:

$\pi=$ Keuntungan usahatani tembakau Virginia $(\mathrm{Rp} / \mathrm{Ha})$;

$\mathrm{TR}$ = Penerimaan total usahatani tembakau Virginia $(\mathrm{Rp} / \mathrm{Ha}) ;$ dan

$\mathrm{TC}$ = Biaya total usahatani tembakau Virginia $(\mathrm{Rp} / \mathrm{Ha})$.

Analisis kelayakan ekonomi usahatani tembakau Virginia di Kabupaten Lombok Tengah digunakan persamaan R/C dan B/C ratio (Soekartawi, 2011; dan Suratiyah, 2015). Analisis R/C Ratio adalah perbandingan penerimaan usahatani dengan biaya total usahatani tembakau virginia yang dinyatakan dengan persamaan

$$
\text { R/C Ratio }=\text { TR/TC }
$$

Dimana:

$\mathrm{R} / \mathrm{C}=$ Revenue Cost (Ratio)

$\mathrm{TR}=$ Total Revenue $(\mathrm{Rp} / \mathrm{Ha})$

$\mathrm{TC}=$ Total Cost $(\mathrm{Rp} / \mathrm{Ha})$ 
Krieria :

- Usahatani tembakau virginia dikatakan layak apabila memiliki nilai R/C Ratio > 1 .

- Usahatani tembakau virginia dikatakan tidak layak apabila apabila nilai R/C Ratio $<1$

- Usahatani tembakau virginia dikatakan kembali modal atau titik impas apabila R/C Ratio = 1

Analisis B/C Ratio adalah perbandingan keuntungan dengan biaya total usahatani tembakau Virginia yang dapat dinyatakan dengan rumus berikut :

$\mathrm{B} / \mathrm{C}$ Ratio $=\mathrm{B} / \mathrm{TC}$

Dimana:

$\mathrm{B} / \mathrm{C}=$ Benefit Cost (Ratio)

$B=$ Benefit $(\mathrm{Rp} / \mathrm{Ha})$

$\mathrm{TC}=$ Total Cost $(\mathrm{Rp} / \mathrm{Ha})$

Kriteria

- Usahatani tembakau virginia dikatakan layak apabila memiliki nilai R/C Ratio > 0 .

- Usahatani tembakau virginia dikatakan tidak layak apabila nilai R/C Ratio < 0

- Usahatani tembakau virginia dikatakan impas apabila R/C Ratio $=0$.

\section{HASIL DAN PEMBAHASAN}

\section{Karakteristik Responden}

Karakteristik responden pada penelitian ini terdiri atas umur peteni, tingkat pendidikan petani, jumlah tanggungan petani dan pengalaman usahatani tembakau petani. Adapaun secara jelas mengenai gambaran umum petani tembakau Virginia di Kabupaten Lombok Tengah disajikan pada tabel 1.

Tabel1. Gambaran umum petani temabaku virginia di Kabupaten Lombok Tengah Tahun 2019

\begin{tabular}{|c|c|c|c|}
\hline No & Karakteristik responden & Jumlah & Persentasi (\%) \\
\hline 1 & $\begin{array}{l}\text { Umur (Tahun) } \\
\quad 15-54 \\
\quad>54\end{array}$ & $\begin{array}{c}21 \\
9\end{array}$ & $\begin{array}{l}70 \\
30 \\
\end{array}$ \\
\hline 2 & $\begin{array}{l}\text { Tingkat Pendidikan } \\
\text { SD } \\
\text { SMP } \\
\text { SMA } \\
\text { Sarjana }\end{array}$ & $\begin{array}{c}14 \\
6 \\
9 \\
1\end{array}$ & $\begin{array}{c}46.67 \\
20 \\
30 \\
3.33\end{array}$ \\
\hline 3 & $\begin{array}{l}\text { Jumlah Tanggungan Keluarga (Orang) } \\
\quad 1-5 \\
\quad>5\end{array}$ & $\begin{array}{c}28 \\
2\end{array}$ & $\begin{array}{c}93.33 \\
6.67\end{array}$ \\
\hline 4 & $\begin{array}{l}\text { Pengalaman Usahatani (Tahun) } \\
\quad 1-10 \\
>10\end{array}$ & $\begin{array}{c}5 \\
25\end{array}$ & $\begin{array}{l}16.67 \\
83.33\end{array}$ \\
\hline
\end{tabular}

Sumber: Data Primer Diolah 2019.

Berdasarkan data Tabel 1, diketahui bahwa umur petani responden berada pada kategori umur produktif sebanyak $70 \%$ dan sisanya sebanyak $30 \%$ tergolong non produktif. Umur responden sangat berpengaruh terhadap kamampuan petani menerima adopsi dan teknologi, semakin produktif umur petani semakin baik dalam menerima adopsi dan teknologi usahatani. Halil (2013) menyataan bahwa umur petani yang produktif berpengaruh dalam menerima adopsi teknologi dan mampu meningkatkan efisiensi teknis. Sebaliknya petani dengan umur non produktif memiliki pengaruh meningkatkan inefisiensi teknis.

Pada penelitian ini tingkat pendidikan petani responden tergolong rendah karena didominasi oleh sekolah dasar sebanyak $46.67 \%$, sedangkan yang terendah adalah lulusan sarjana yang hanya sebesar 3.33\%. Nursan (2015) menyatakan bahwa tingkat pendidikan berpengaruh dalam meningkatkan produktivitas dan efisiensi usahatani karena pendidikan dapat mendorong petani untuk mengadopsi teknologi dan produksi pertanian.

Tanggungan keluarga adalah semua anggota dalam keluarga yang hidupnya masih bergantung pada petani sebagai kepala keluarga. Jika anggota keluarga yang menjadi tanggungan banyak, maka petani akan melakukan usaha keras untuk dapat menggung kebutuhan tanggungannya. Pada penelitian ini menunjukkan bahwa bahwa 93,00\% tanggungan keluarga petani tergolong dalam keluarga kecil dan $6.67 \%$ tergolong dalam keluarga besar. 
Faktor pengalaman petani adalah faktor penting bagi petani dalam melakukan dan mengembangakan usahatani karena jika petani berpengalaman akan mampu mengatasi permasalahan yang dihadapi dalam melakukan usahatani (Tuwo, 2011). Berdasarkan data pada Tabel 1 menunjukkan bahwa petani responden tergolong petani yang berpengalaman karena sebanyak $83.33 \%$ petani memiliki pengalaman lebih dari 10 tahun dalam melakukan usahatani tembakau virginia.

\section{Biaya Usahatani Tembakau Virginia}

Biaya usahatani tembakau Virginia pada penelitian ini merupakan total biaya usahatani tembakau Virginia yang dikeluarkan dalam satu kali musim tanam. Menurut (Fauziyah et al., 2010) total biaya usahatani ini merupakan nilai semua faktor produksi usahatani tembakau Virginia yang dikeluarkan baik berupa penggunaan barang ataupun jasa. Adapun biaya usahatani usahatani tembakau Virginia di Kabupaten Lombok Tengah secara jelas disajikan pada Tabel 2

Tabel 2. Biaya rata-rata usahatani tembakau virginia di Kabupaten Lombok Tengah Tahun 2019.

\begin{tabular}{|c|c|c|c|c|}
\hline \multirow{2}{*}{ No } & \multirow{2}{*}{ Jenis Biaya } & \multirow{2}{*}{ Satuan } & \multicolumn{2}{|c|}{ Nilai Input Per Hektar } \\
\hline & & & Jumlah Fisik & Nilai (Rp) \\
\hline A & Biaya Variabel & & & \\
\hline 1 & Sarana Produksi & & & \\
\hline & a. Bibit Tembakau Viarginia & $(\mathrm{Kg})$ & 2.81 & $128,222.22$ \\
\hline & b. Pupuk & (Kg) & 938.89 & $4,406,944.44$ \\
\hline & c. Pestisida & (liter) & 13.54 & $766,055.56$ \\
\hline & Total Sarana Produksi & $(\mathrm{Rp})$ & 955.24 & $5,301,222.22$ \\
\hline 2 & Tenaga Kerja & & & \\
\hline & a. TKDK & (HKO) & 60.54 & $4,148,472.22$ \\
\hline & b. TKLK & (HKO) & 308.65 & $27,778,555.56$ \\
\hline & Total Tenaga Kerja & $(\mathrm{Rp})$ & 369.19 & $31,927,027.78$ \\
\hline 3 & Biaya Lain-lain & $(\mathrm{Rp})$ & & $7,538,055.56$ \\
\hline B & Biaya Tetap & & & \\
\hline 1 & Penyustan Alat & (Rp) & & $2,355,737.35$ \\
\hline 2 & Sewa Lahan & $(\mathrm{Rp})$ & & $555,555.56$ \\
\hline 3 & Pajak Tanah & (Rp) & & $292,083.33$ \\
\hline & Total Biaya Tetap & (Rp) & & $3,203,376.24$ \\
\hline & Total Biaya Usahatani & $(\mathrm{Rp})$ & & $47,969,681.79$ \\
\hline
\end{tabular}

Sumber: Data Primer Diolah 2019.

Berdasarkan Tabel 2, diketahui bahwa biaya rata-rata usahatani tembakau virginia satu musim di Kabupaten Lombok Tengah sebesar Rp. 47.969.681,79 per hektar. Biaya usahatani tersebut meliputi biaya variabel dan biaya tetap. Secara keseluruhan biaya pada penelitian ini masih lebih besar apabila dibandingkan dengan biaya usahatani tembaku virginia yang ditemukan pada penelitian Halil (2013) yaitu sebesar Rp 46.095.054.

Besarnya total biaya usahatani yang dikeluarkan pada usahatani tembakau virginia di Kabupaten Lombok Tengah ini dikarenakan penggunaan tenaga kerja yang banyak atau merupakan jenis usahatani padat karya Halil (2013), dimana biaya tenaga kerja mulai dari pengolahan tanah, penanaman, pemeliharaan, pemanenan, pembersihan sampai kegiatan pengomprongan mencapai sebesar Rp. 31.927.027,8 per hektar dalam satu musim. Biaya rata-rata tenaga kerja pada usahatani tembakau Virginia di Kabupaten Lombok Tengah ini masih lebih besar apabila dibandingkan dengan penelitian terdahulu yang dilakukan oleh (Nazam et al., 2014), dengan biaya total tenaga kerja usahatani tembakau Virginia sebesar Rp. 21.380.000.

\section{Penerimaan dan Keuntungan Usahatani Tembakau Virginia}

Penerimaan usahatani tembakau Virginia merupakan nilai produksi tembakau Virginia yang diterima petani dalam satu musim tanam.. Sedangkan keuntungan usahatani merupakan selisih dari penerimaan dan total biaya usahatani (Soekartawi, 2011;dan Suratiyah, 2015). Adapun besar penerimaan dan keuntungan usahatani tembakau virginia di Kabupaten Lombok Tengah disajikan secara jelas pada Tabel 3. 
Tabel 3. Rata-rata penerimaan, total biaya dan keuntungan usahatani tembakau virginia di Kabupaten Lombok Tengah Tahun 2019.

\begin{tabular}{clcc}
\hline No & Uraian & Satuan & $\begin{array}{c}\text { Petani Tembakau Virginia } \\
\text { Per Hektar }\end{array}$ \\
\hline 1 & Produksi & $\mathrm{Kg}$ & $2,081.94$ \\
2 & Harga & $\mathrm{Rp} / \mathrm{Kg}$ & $43,382.35$ \\
3 & Penerimaan & $\mathrm{Rp}$ & $90,319,444.44$ \\
4 & Total Biaya Produksi & $\mathrm{Rp}$ & $47,969,681.79$ \\
5 & Keuntungan & $\mathrm{Rp}$ & $42,349,762.65$ \\
\hline
\end{tabular}

Sumber: Data Primer Diolah 2019.

Tabel 3 menunjukkan rata-rata penerimaan petani dalam melakukan usahatani tembakau Virginia di Kabupaten Lombok Tengah sebesar Rp. 90.319.444,44 per hektar dan biaya rata-rata usahatani tembakau Virginia sebesar Rp. 47.969.681,79 per hektar. sehingga diperoleh keuntungan petani tembakau virginia sebesar Rp. 42.349.762,65 per hektar. Keuntungan usahatani tembakau Virginia pada penelitian ini masih lebih besar dari keuntungan usahatani tembakau Virginia pada penelitian Halil (2013) sebesar Rp. 12.781 .197 per hektar dan Nazam et al., (2014) sebesar Rp.14.142.500 per hektar. Hal ini dikarenakan tingkat pengalaman usahatani yang tergolong tinggi jika dibandingkan dengan penelitian sebelumnya, tingkat adopsi teknologi dan inovasi petani yang memadai serta petani dalam melakukan usahatani tembakau Virginia pada lahan sawah setelah tanaman padi . Begitu juga jika dibandingkan dengan keuntungan usahatani tembakau non virginia juga masih lebih besar seperti keuntungan usahatani tembakau rakyat pada penelitian Estariza, et al., (2013) sebesar Rp16.820.881,79 per hektar, Tarigan et al., (2013) sebesar Rp 26. 857.694.87 per hektar (Putri et al., 2015) adalah sebesar Rp.12.387.619,90 per hektar dan sebesar Rp 21.051.624,77 per hektar (Manalu et al., 2018). . Hal ini dikarenakan produktivitas dan harga tembakau Virginia di pasaran tergolong lebih tinggi jika dibandingkan dengan tembakau rakyat.

\section{Kelayakan Ekonomi Usahatani Tembakau Virginia}

Analisis kelayakan ekonomi usahatani tembakau Virginia pada penelitian ini diukur dengan menggunakan analisis $\mathrm{R} / \mathrm{C}$ ratio dan $\mathrm{B} / \mathrm{C}$ Ratio. Analisis $\mathrm{R} / \mathrm{C}$ ratio adalah perbandingan total penerimaan dengan total biaya usahatani, sedangkan analisis $\mathrm{B} / \mathrm{C}$ ratio adalah perbandingan keuntungan dengan total biaya usahatani (Soekartawi, 2011; dan Suratiyah, 2015).. Adapun hasil kelayakan ekonomi usahatani tembakau Virginia di Kabupaten Lombok Tengah Secara jelas disajikan pada Tabel 4.

Tabel 4. Kelayakan ekonomi usahatani tembakau virginia di Kabupaten Lombok Tengah Tahun 2019

\begin{tabular}{ccc}
\hline No & Kelayakan Ekonomi & Nilai \\
\hline 1 & $\mathrm{R} / \mathrm{C}$ ratio & 1.9 \\
2 & $\mathrm{~B} / \mathrm{C}$ ratio & 0.9 \\
\hline
\end{tabular}

Sumber: Data Primer Diolah 2019.

Tabel 4 menunjukkan usahatani tembakau Virginia di Kabupaten Lombok Tengah memiliki kelayakan ekonomi . berdasrkan hasil analisis diperoleh nilai $\mathrm{R} / \mathrm{C}$ ratio $>1$ dan $\mathrm{B} / \mathrm{C}$ Ratio $>0$. Nilai analisis $\mathrm{R} / \mathrm{C}$ ratio sebesar 1.9 artinya besar penerimaan petani setiap satuan biaya usahatani yang dikeluarkan. Sedangkan nilai analisis B/C ratio sebesar 0.9 artinya besar keuntungan petani dari setiap satuan biaya usahatani yang dikeluarkan. Hasil analisis kelayakan ekonomi pada penelitian ini masih lebih besar dari hasil analisis kelayakan usahatani temabakau Virginia lainnya seperti pada penelitian (Halil, 2013) nilai R/C ratio sebesar 1.3 dan B/C ratio sebesar 0.28 , dan penelitian Nazam et al., (2014) nilai $\mathrm{R} / \mathrm{C}$ ratio sebesar 1.43 dan $\mathrm{B} / \mathrm{C}$ ratio sebesar 0.43 . Hal ini sangat dipengaruhi oleh pengalaman usahatani yang tergolong tinggi jika dibandingkan dengan penelitian sebelumnya, tingkat adopsi teknologi dan inovasi petani yang memadai serta jenis lahan petani yang digunakan pada usahatani tembakau Virginia.

\section{KESIMPULAN}

Berdasarkan tujuan dan pembahasan penelitian dapat disimpulkan bahwa usahatani tembakau Virginia di Kabupaten Lombok Tengah merupakan usahatani yang menguntungkan dengan keuntungan rata-rata usahatani yang dihasilkan dalam satu musim tanam sebesar Rp. 42.349 .763 per hektar. Usahatani Tembakau Virginia di Kabupaten Lombok Tengah memiliki nilai kelayakan 
ekonomi yaitu $\mathrm{R} / \mathrm{C}$ ratio memiliki nilai 1.9 dan nilai $\mathrm{B} / \mathrm{C}$ ratio sebesar 0.9 . Tingkat keuntungan dan kelayakan yang tinggi ini dipengaruhi oleh tingginya pengalaman petani, dan adopsi teknologi dan inovasi serta tenaman tembakau dilakukan pada lahan sawah yang memiliki irigasi yang baik.

\section{REFERENSI}

Ambariyanto, \& Herawati, N. (2010). Pengembangan Kelembagaan Pemasaran Komoditas Tembakau terhadap Kesejahteraan Petani di Kabupaten Sumenep. Jurnal Akuntansi, Manajemen Bisnis Dan Sektor Publik, 7(1), 21-45.

BPS Kabupaten Lombok Tengah. (2018). Kabupaten Lombok Tengah dalam Angka Tahun 2018. Badan Pusat Statistik Kabupaten Lombok Tengah.

BPS Provinsi NTB. (2018). Provinsi Nusa Tenggara Barat dalam Angka Tahun 2018. Badan Pusat Statistik Provinsi Nusa Tenggara Barat.

Brata, W. (2012). Tembakau atau Mati Kesaksian, Kegelisahan dan Harapan Seorang Petani Tembakau. Penerbit Indonesia Berdikari.

Cahyono, B. (2011). Untung Selangit dari Usaha bertanam Tembakau. Cahya Atma Pustaka.

Dirjenbun. (2014). Luas Tanam dan Produktivitas Tanaman Perkebunan di Indonesia. Direktorat Jenderal Perkebunan.

Djajadi, D. (2015). Tobacco Diversity in Indonesia. Journal of Biological Researches, 20(2), 27-32. https://doi.org/10.23869/bphjbr.20.2.20155

Estariza, Erzia, Prasmatiwi, E, Fembriarti, Santoso, H. (2013). Efisiensi Produksi Dan Pendapatan Usahatani Tembakau Di Kabupaten Lampung Timur. Jiia, 1(3), 264-270.

Fauziyah, E., Hartoyo, S., Kusnadi, N., \& Kuntjoro, S. U. (2010). Analisis Produktivitas Usahatani Tembakau di Kabupaten Pamekasan. Jurnal Organisasi Dan Manajemen, 6(2), 119-131.

Halil. (2013). Pengaruh Kemitraan Terhadap Efisiensi Tembakau Virginia di Pulau Lombok Nusa Tenggara Barat. Institut Pertanian Bogor.

Hamidi, H. (2010). the Impact of Contract Farming on the Profit of Virginia Tobacco Farming in Lombok Island, West Nusa Tenggara. Jurnal Ekonomi \& Bisnis Indonesia (Fakultas Ekonomi Dan Bisnis Universitas Gadjah Mada), 25(1), 29-40. https://doi.org/10.22146/jieb.6301

Hasan, F., \& Darwanto, H. (2013). Prospek dan Tantangan Usahatani Tembakau Madura. Sepa, 10(September 2013), 63-70.

Hayati, M., \& Maisaroh, S. (2019). Faktor-Faktor Yang Mempengaruhi Keputusan Petani dalam Pemilihan Komoditas (Studi Kasus Pada Tanaman Tembakau dan Padi Di Kabupaten Pamekasan). 12(2), 84-92.

Kementerian Perindustrian. (2016). Kontribusi Besar Industri Hasil Tembakau Bagi Ekonomi Nasional. Kementerian Perindustrian Republik Indonesia. https://kemenperin.go.id/artikel/17257/Kontribusi-Besar-Industri-Hasil-Tembakau-BagiEkonomi-Nasional

Manalu, A. S., Sumantri, B., \& Priyono, B. S. (2018). Pendapatan Berdasarkan Status Penguasaan Lahan Usahatani Tembakau Dan Pemasarannya. Jurnal AGRISEP, 17(1), 63-78. https://doi.org/10.31186/jagrisep.17.1.63-78

Nazam, M., Suriadi, A., \& Sahram. (2014). Analisis Ekonomi Usaha Tani Tembakau Virginia dan Permasalahannya di Nusa Tenggara Barat (Kasus di Kabupaten Lombok Timur). Semiloka Nasional Tanaman Pemanis,Serat, Tembakau, Dan Minyak Industri Pusat Penelitian Dan Pengembangan Perkebunan, 179-188.

Nursan, M. (2015). Efisiensi dan Daya Saing Usahatani Jagung Pada Lahan Kering dan Sawah di Kabupaten [Institut Sumbawa Pertanian Bogor]. https://repository.ipb.ac.id/handle/123456789/74832

Nursan, M., \& Utama, F. A. (2019). Strategi Pengembangan Badan Usaha Milik Desa (Bumdes) Berbasis Pertanian Di Kabupaten Sumbawa Barat. 8(2), 67-78. https://doi.org/http://dx.doi.org/10.26418/j.sea.v8i2.37726

Putri, E. A., Suwandari, A., \& Ridjal, J. A. (2015). Analisis Pendapatan dan Efisiensi Biaya Usahatani Tembakau Maesan 2 di Kabupaten Bondowoso. 8(1), 64-69.

Soekartawi. (2011). IImu Usahatani dan Penelitian Untuk Pengembangan Petani Kecil. UI Press.

Sugiono. (2017). Metode Penelitian Kuantitatif, Kualitatif, dan R\&D. Alfabeta.

Sumartono, E. (2016). Analisis Produksi Tembakau Rajangan Rakyat Tipe Muntilanan dan Tipe Magelangan Dalam Pola Kemitraan CV.Merabu - PT. Djarum Kudus. 15(2), 263-277. http://nbn-resolving.de/urn:nbn:de:0001jagrisep.15.2.263-2778

Suratiyah, K. (2015). IImu Usahatani. Penebar Swadaya. 
Suwarso. (2014). Source of Tobacco Genetic: Management Status and Application (in Source of Genetic Agri-culture: Food, Estate, and Horticulture Crops. IAARD Press, 165-185.

Tarigan, J. L., Salmiah, \& Fauziah, L. (2013). Analisis Kelayakan Usahatani Tembakau Rakyat. Journal On Social Economic Of Agriculture And Agribusiness, 2(11), 1-14. https://jurnal.usu.ac.id/index.php/ceress/article/view/8037

Tuwo, M. A. (2011). IImu Usahatani: Teori dan Aplikasi Menuju Sukses. Unhalu Press.

Winarso, B. (2012). Dinamika Pola Penguasaan Lahan Sawah di Wilayah Pedesaan di Indonesia Pattern Dynamics Control Wetland in Rural Areas in Indonesia. Jurnal Penelitian Pertanian Terapan, 12(3), 137-149. 